\title{
Effects of n-3 polyunsaturated fatty acids on malignant ventricular arrhythmias in patients with chronic heart failure and implantable cardioverter-defibrillators: A substudy of the Gruppo Italiano per lo Studio della Sopravvivenza nell'Insufficienza Cardiaca (GISSI-HF) trial
}

Andrea A. Finzi, MD, ${ }^{a}$ Roberto Latini, MD,${ }^{b}$ Simona Barlera, MSc, ${ }^{\mathrm{b}}$ Maria G. Rossi, MD, ${ }^{\mathrm{c}, \mathrm{k}}$ Albarosa Ruggeri, MD, ${ }^{\mathrm{d}, \mathrm{k}}$ Alessandro Mezzani, MD, ${ }^{e, k}$ Chiara Favero, BSc, ${ }^{\mathbf{b}}$ Maria G. Franzosi, BiolD, ${ }^{\mathbf{b}}$ Domenico Serra, MD, Donata Lucci, MSc, ${ }^{\mathbf{f}}$ Francesca Bianchini, BSc, ${ }^{\mathrm{f}}$ Roberto Bernasconi, ${ }^{\mathrm{b}}$ Aldo P. Maggioni, MD, ${ }^{\mathrm{f}}$

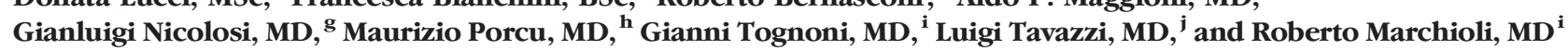
Milano, Reggio Calabria, Veruno, Florence, Pordenone, Cagliari, S Maria Imbaro, and Cotignola, Italy; and Lugano, Switzerland

Background The antiarrhythmic effects of $n-3$ polyunsaturated fatty acids (n-3PUFA) in ischemic heart disease have been demonstrated; however, studies in patients surviving malignant ventricular arrhythmias of different etiologies treated with an implantable cardioverter-defibrillator (ICD) have given conflicting results. The purpose of this study was to assess the antiarrhythmic effect of n-3PUFA versus placebo in 566 patients with heart failure enrolled in the GISSI-HF trial who received an ICD for secondary or primary prevention of ventricular fibrillation (VF) or tachycardia (VT).

Methods Clinical data and arrhythmic event recordings extracted from the device memory were obtained. We tested the treatment effect by a multivariate Cox model adjusting for all clinical parameters associated with the primary end point defined as time to first appropriate ICD discharge for VT/VF.

Results In the 566 patients with at least one recorded follow-up visit, 1363 VT and 316 VF episodes were terminated by ICD pacing or shock over a median follow-up of 928 days. The incidence of the primary end point event was $27.3 \%$ in the n-3PUFA group and $34.0 \%$ in the placebo group (adjusted hazard rate $=0.80,95 \% \mathrm{Cl} 0.59-1.09, \mathrm{P}=.152$ ). Patients who received 1,2 to 3 , or $>3$ ICD discharges were $8.9 \%, 7.1 \%$, and $11.1 \%$ in the n-3PUFA group, compared with slightly higher rates of $11.1 \%, 10.7 \%$, and $12.1 \%$ in the placebo group (overall $P=.30$ ). Patients with the highest 3 -month increase in plasma n-3PUFA had a somewhat lower incidence of arrhythmic events.

Conclusions The results of this study, though not statistically significant, support prior evidences of an antiarrhythmic effect of $n$-3PUFA in patients with ICD, although they leave open the issue of whether this effect leads to a survival benefit. (Am Heart J 2011;161:338-343.e1.)

Patients with chronic heart failure (HF) and low left ventricular ejection fraction (LVEF) are at a significantly elevated risk of sudden cardiac death. Recent guidelines

From the a Unit of Cardiovascular Medicine, Cardiopulmonary Dept, Fondazione Ca' Granda/Policlinico, Milano, Italy, Istituto Mario Negri, Milano, Italy, 'C Cardiocentro Ticino, Lugano, Switzerland, 'Policlinico Madonna della Consolazione, Reggio Calabria, Italy, ${ }^{e}$ Fondazione Salvatore Maugeri, Veruno, Italy, ${ }^{f}$ ANMCO Research Center, Florence, Italy, ${ }^{g}$ AO S Maria Angeli, Cardiology Unit, Pordenone, Italy, ${ }^{h}$ AO Brotzu-S Michele, Cagliari, Italy, 'Consorzio Mario Negri Sud, S Maria Imbaro, Italy, and 'Maria Cecilia Hospital, GVM Care and Research, Ettore Sansavini Health Science Foundation, Cotignola, Italy. ${ }^{k}$ On behalf of the Investigators of the ICD substudy of GISSI-HF. See the online Appendix for complete listing.

ClinicalTrials.gov Identifier: NCT00336336 (for the main study). strongly support a primary prevention strategy based on implantable cardiac defibrillators (ICDs). ${ }^{1}$ The introduction of cardiac resynchronization therapy (CRT) with

\footnotetext{
The GISSI Studies are endorsed by the Associazione Nazionale Medici Cardiolog Ospedalieri (ANMCO), by the Istituto di Ricerche Farmacologiche "Mario Negri", and by the Consorzio Mario Negri Sud, Italy. Submitted May 14, 2010; accepted October 15, 2010

Reprint requests: Roberto Latini, MD, Department of Cardiovascular Research, Istituto di Ricerche Farmacologiche Mario Negri, Via La Masa 19, 20156 MILANO, Italy. E-mail: roberto.latini@marionegri.it

0002-8703/\$ - see front matter

(C) 2011 , Mosby, Inc. All rights reserved.

doi:10.1016/i.ahj.2010.10.032
} 
biventricular pacemakers in HF patients nonresponsive to optimal medical therapy has expanded the number of subjects who receive an ICD as backup for primary prevention, as both treatments can be combined in the same pacing system. ${ }^{2}$

Epidemiological studies indicate that intake of marine long-chain $n-3$ polyunsaturated fatty acids ( $n-3 P U F A$ ) is associated with a reduction in cardiovascular (CV) mortality. This is supported by a number of basic studies providing evidence that $n$-3PUFA reduce surrogate markers of arrhythmia driven by $\mathrm{Ca}^{2+}$ overload. ${ }^{3}$ The Gruppo Italiano per lo Studio della Sopravvivenza nell'Infarto miocardico (GISSI)-Prevenzione trial found a lower overall mortality, mostly attributable to fewer sudden cardiac deaths among patients treated with n-3PUFA after myocardial infarction (AMI) compared with controls. ${ }^{4}$ GISSI-HF was the first large-scale, randomized, placebo-controlled trial showing that n-3PUFA can reduce mortality and $\mathrm{CV}$ hospitalization in patients with symptomatic HF of any etiology and with any level of LVEF. ${ }^{5}$ A recent reanalysis of GISSI-HF showed that fatal and nonfatal ventricular arrhythmic events were significantly reduced by n-3PUFA treatment. ${ }^{6}$ However, 3 trials in patients with an ICD implanted after malignant ventricular tachycardia (VT) or ventricular fibrillation (VF) of different etiology failed to demonstrate a significant reduction of ICD interventions or of mortality with n-3PUFA, even after pooled analysis. ${ }^{7-11}$ As a sizable proportion of GISSI-HF patients had an ICD implanted before or after entering the main trial, we report here the results of a substudy, designed and conducted in parallel to the main one, investigating the antiarrhythmic effect of n-3PUFA in HF patients with implanted ICD.

\section{Methods}

Eighty-nine of the 325 centers participating in the GISSI-HF trial accepted to collect an additional set of data on their clinical history with respect to ICD management and reasons for ICD discharge. Patients who had an ICD implanted before entering the main trial or after randomization, either for a history of cardiac arrest, sustained VT, or syncope of suspected tachyarrhythmic origin or for primary prevention, were eligible for this substudy. Data were prospectively collected over the last period of the study, from September 2004 to December 2007.

\section{Study end points}

The primary end points were time to an appropriate ICD intervention for major arrhythmias, that is, shock at high or low intensity or overdrive pacing for spontaneous ventricular tachyarrhythmia, either VT or VF, and the number of VT and VF episodes. Other end points were total and CV mortality, total hospitalizations, and hospitalizations for CV events (ie, worsening of HF, arrhythmias, and other CV causes). The ICD data were reviewed by a central ICD Core Laboratory for validation of arrhythmic events to rule out inappropriate ICD electrical treatment and to characterize the detected and treated pathologic electrograms. The clinical events recorded in the study were adjudicated blindly by an ad hoc committee on the basis of agreed definitions and procedures. All reports included a narrative summary with supporting documentation for every event (eg, clinical records, death certificates, and other relevant documentation). ${ }^{12}$

\section{Procedures}

Patients were randomly assigned to receive 1 capsule per day of $1 \mathrm{~g} \mathrm{n}$-3PUFA (850 mg eicosapentaenoic acid and docosahexaenoic acid as ethyl esters in the average ratio of $1.2: 1$ ) or matching placebo. Patients eligible for the main GISSI-HF trial were randomized from August 6, 2002, to February 28, 2005. Patients were scheduled for clinical visits at 1,3,6, and then every 6 months until the end of the trial.

The present substudy was conducted from September 2004 to the end of the main study, December 2007, in 89 centers. As patients could be admitted to the ICD substudy at any time, hospitalizations before ICD implant as well as those scheduled for ICD implant or maintenance were discarded from the analysis. The ICD programming was left to the cardiologist's decision. At each follow-up visit, the ICD was interrogated by telemetry; and the data were stored. Data from unscheduled visits for clinical events were also collected to ensure complete follow-up of ICD data. Blood samples for plasma levels of $n-3$ PUFA were obtained at baseline and after 3 months in 159 of the 566 patients enrolled in the ICD substudy. ${ }^{13}$

\section{Statistical methods}

Baseline characteristics for randomized treatments, expressed as proportions, were compared by the $\chi^{2}$ test for categorical variables and by the $t$ test for continuous variables. To estimate the effect of n-3PUFA on the primary end point, univariate and multivariable Cox proportional hazards models were fitted. Multivariable analysis was adjusted for baseline variables that were significantly related with the outcome at univariate analysis $(P$ value $<.05)(\mathrm{eg}, \mathrm{sex}$, smoking, history of atrial fibrillation, hemoglobin $\leq 12 \mathrm{~g} / \mathrm{dL}$, previous pacemaker, previous ICD, previous percutaneous coronary intervention, bundle-branch block, pulmonary rales, hematocrit, use of direct-acting vasodilating agents). Kaplan-Meier estimates for the time to first appropriate ICD intervention by treatment were presented and compared by the Wilcoxon test. Time to outcome event was computed either from the time of randomization to the main trial, for patients implanted before entering GISSI-HF, or from time of ICD implant, for patients implanted during follow-up. Treatment effect was also analyzed for secondary end points by univariate and multivariable Cox models, adjusting for covariates associated with the outcome of interest. Treatment effects on changes of $n-3$ and $n-3 / n-6$ fatty acids from baseline were analyzed by analysis of variance, adjusting for their baseline value. Analyses were done with SAS software (version 9.1; SAS, Cary, NC).

\section{Sources of funding}

The GISSI-HF main study was supported by AstraZeneca, SPA, Pfizer, Sigma-Tau, and Pharmacia. The present substudy was planned, conducted, and analyzed without specific financial support by the GISSI group that has full ownership of the data, in complete independence from the sponsors. The authors are 
Table I. Baseline characteristics and treatment in the ICD substudy population and in the overall GISSI-HF study

\begin{tabular}{|c|c|c|c|c|}
\hline & n-3PUFA (n = 278) & Placebo (n = 288) & P value $^{*}$ & $\begin{array}{l}\text { Overall study } \\
(N=6975)\end{array}$ \\
\hline Age $(y)$, mean $\pm S D$ & $64.9 \pm 9.5$ & $64.8 \pm 9.8$ & .9149 & $67 \pm 11$ \\
\hline Age $>70 y, n(\%)$ & $91(32.7)$ & $86(30.0)$ & .4611 & $2947(42.3)$ \\
\hline Women, $\mathrm{n}(\%)$ & $28(10.1)$ & 38 (13.2) & .2472 & $1516(21.7)$ \\
\hline Smokers, n (\%) & $39(14.0)$ & $50(17.4)$ & .2763 & $987(14.1)$ \\
\hline History of hypertension, n (\%) & $113(40.7)$ & $143(49.7)$ & .0314 & $3809(54.6)$ \\
\hline \multicolumn{5}{|l|}{ NYHA class, $\mathrm{n}(\%)$} \\
\hline$\|$ & $176(63.3)$ & $186(64.6)$ & .8033 & $4425(63.4)$ \\
\hline III & $101(36.3)$ & $100(34.7)$ & & 2365 (33.9) \\
\hline IV & $1(0.4)$ & $2(0.7)$ & & $187(2.7)$ \\
\hline $\operatorname{LVEF}(\%)$, mean \pm SD & $28.1 \pm 6.5$ & $28.7 \pm 6.9$ & .2258 & $33 \pm 8.5$ \\
\hline LVEF $>40 \%, n(\%)$ & $5(1.8)$ & $5(1.7)$ & .9550 & $653(9.4)$ \\
\hline $\begin{array}{l}\text { Admission for } \mathrm{HF} \text { in previous } \\
\text { year, } \mathrm{n}(\%)\end{array}$ & $120(43.2)$ & $111(38.5)$ & .2632 & $3384(48.5)$ \\
\hline Previous AMI, n (\%) & $161(57.9)$ & $162(56.2)$ & .6893 & 2909 (41.7) \\
\hline Stroke, n (\%) & $13(4.7)$ & $22(7.6)$ & .1435 & $346(5.0)$ \\
\hline Diabetes mellitus, n (\%) & $65(23.4)$ & 77 (26.7) & .3574 & $1974(28.3)$ \\
\hline CABG, n (\%) & $74(26.6)$ & $82(28.5)$ & .6218 & $1271(18.2)$ \\
\hline $\mathrm{PCl}, \mathrm{n}(\%)$ & $58(20.9)$ & $63(21.9)$ & .7691 & $866(12.4)$ \\
\hline$I C D, \mathrm{n}(\%)$ & $129(46.4)$ & $129(44.8)$ & .7004 & $497(7.1)$ \\
\hline Pacemaker, n (\%) & $62(22.3)$ & $68(23.6)$ & .7113 & $892(12.8)$ \\
\hline History of atrial fibrillation, n (\%) & 45 (16.2) & 44 (15.3) & .7664 & $1325(19.0)$ \\
\hline Peripheral vascular disease, n (\%) & $17(6.1)$ & $30(10.4)$ & .0637 & $610(8.8)$ \\
\hline Neoplasia, n (\%) & $15(5.4)$ & $8(2.8)$ & .1148 & $265(3.7)$ \\
\hline \multicolumn{5}{|l|}{ Medical treatment } \\
\hline ACE inhibitors, $n(\%)$ & 209 (75.2) & $223(77.4)$ & .5289 & $5374(77.1)$ \\
\hline$A R B s, n(\%)$ & $64(23.0)$ & $55(19.1)$ & .2520 & 1321 (18.9) \\
\hline ACE inhibitors/ARBs, $\mathrm{n}(\%)$ & $264(94.7)$ & 273 (94.8) & .9259 & 6520 (93.5) \\
\hline$\beta$-Blockers, n (\%) & $214(77.0)$ & $223(77.4)$ & .8980 & $4522(64.8)$ \\
\hline Spironolactone, n (\%) & $125(45.0)$ & $136(47.2)$ & .5900 & $2740(39.3)$ \\
\hline Diuretics, n (\%) & $254(91.4)$ & $270(93.8)$ & .2795 & $6260(89.8)$ \\
\hline Digitalis, n (\%) & $97(34.9)$ & $90(31.3)$ & .3571 & $2588(37.1)$ \\
\hline Oral anticoagulants, n (\%) & $110(39.6)$ & $102(35.4)$ & .3076 & $2009(28.8)$ \\
\hline Aspirin, $\mathrm{n}(\%)$ & $130(46.8)$ & $136(47.2)$ & .9128 & $3358(48.1)$ \\
\hline Other antiplatelet agents, $n(\%)$ & $24(8.6)$ & $43(14.9)$ & .0204 & $716(10.3)$ \\
\hline Nitrates, $n(\%)$ & $85(30.6)$ & $96(33.3)$ & .4819 & $2472(35.4)$ \\
\hline Amiodarone, $\mathrm{n}(\%)$ & $106(38.1)$ & $98(34.0)$ & .3096 & $1358(19.5)$ \\
\hline Calcium-channel blockers, n (\%) & $12(4.3)$ & $17(6.0)$ & .3922 & 709 (10.2) \\
\hline Statin (open), n (\%) & 95 (34.17) & $83(28.8)$ & .1703 & $1579(22.6)$ \\
\hline
\end{tabular}

NYHA, New York Heart Association; $A M l$, acute myocardial infarction; $C A B G$, coronary artery bypass graft; $P C l$, percutaneous coronary intervention; $A C E$, angiotensin-converting enzyme; $A R B$, angiotensin receptor blocker.

*Comparisons are between n-3PUFA and placebo groups only in the ICD substudy.

solely responsible for the design and conduct of this study, all study analyses, the drafting and editing of the paper, and its final contents.

\section{Results}

\section{Patient population}

Of the 566 patients with at least one recorded follow-up visit and therefore analyzable within the GISSI-HF ICD study, 278 were assigned to receive n-3PUFA and 288 to placebo. Follow-up was concluded on December 31, 2007. The median follow-up duration was 928 days (quartiles 1-3 521-1287 days). Table I shows the baseline demographic characteristics including medical treatment of the n-3PUFA and placebo arms of the ICD study. Whereas no differences were observed between patients in the treatment and placebo arms of the ICD patient population, with the exception of history of hypertension and antiplatelet use, this subgroup was younger than the main study population and more severely ill.

At randomization, 233 patients had already an ICD (41\%); and it was implanted during the follow-up in the other 333 (172 in placebo and 161 in n-3PUFA group). Indications for ICD implant were secondary prevention in $27.5 \%$, primary prevention in $56.6 \%$, and syncope of suspected arrhythmic etiology in $15.9 \%$ (Table II). Primary prevention increasingly became the main indication for implant during the study. Similarly, an increasing number of biventricular devices with ICD backup were implanted in 219 patients (39.0\%). Baseline characteristics as well as the effect of n-3PUFA on main outcome were similar for patients who had a first ICD implant and those with an ICD already present at randomization. 
Table II. Indications for ICD implant by time of implant

\begin{tabular}{|c|c|c|c|}
\hline $\begin{array}{l}\text { Postrandomization } \\
\text { implant }\end{array}$ & $\begin{array}{c}\text { n-3PUFA } \\
\text { (161) }\end{array}$ & $\begin{array}{l}\text { Placebo } \\
\text { (172) }\end{array}$ & $P$ value \\
\hline $\begin{array}{l}\text { Syncope, } \mathrm{n}(\%) \\
\text { Primary prevention, } \mathrm{n}(\%) \\
\text { Secondary prevention, } \mathrm{n}(\%) \\
\text { CRT, } \mathrm{n}(\%)\end{array}$ & $\begin{array}{r}21(13.6) \\
102(65.8) \\
32(20.7) \\
68(42.2)\end{array}$ & $\begin{array}{r}21(12.6) \\
118(70.7) \\
28(16.8) \\
78(46.2)\end{array}$ & .61 \\
\hline $\begin{array}{l}\text { Prerandomization } \\
\text { implant }\end{array}$ & $\begin{array}{c}\text { n-3PUFA } \\
(117)\end{array}$ & $\begin{array}{l}\text { Placebo } \\
\text { (1 16) }\end{array}$ & $P$ value \\
\hline $\begin{array}{l}\text { Syncope, n (\%) } \\
\text { Primary prevention, n (\%) } \\
\text { Secondary prevention, } \mathrm{n}(\%) \\
\text { CRT, n (\%) }\end{array}$ & $\begin{array}{l}27(23.7) \\
40(35.1) \\
47(41.2) \\
32(27.6)\end{array}$ & $\begin{array}{l}18(15.9) \\
51(45.1) \\
44(38.9) \\
41(35.3)\end{array}$ & .20 \\
\hline
\end{tabular}

\section{ICD interventions}

During follow-up, 174 (30.7\%) patients had at least one episode of appropriate ICD intervention. As shown in the Kaplan-Meier curves, the incidence of ICD interventions in the n-3PUFA group was somewhat lower than that in the placebo group, respectively (76 [27.3\%] and 98 patients [34.0\%] in the placebo group; Wilcoxon test $P=.146$ ) (Figure 1). Time to first ICDtreated arrhythmic event showed a tendency, not statistically significant, toward lower risk of ICD discharge in patients treated with n-3PUFA (unadjusted hazard rate $[\mathrm{HR}] 0.82,95 \%$ CI $0.61-1.11, P=.210$; adjusted HR 0.80, 95\% CI 0.59-1.09, $P=.152$ ).

A total of 1693 ICD-treated episodes of VT/VF were recorded during the follow-up: 1363 (80.5\%) VT, 316 (18.7\%) VF, and $14(0.8 \%)$ not defined. ICD-driven therapy for VT episodes was recorded in 143 patients, $61(22.0 \%)$ in the treatment group and $82(28.5 \%)$ in the placebo group (unadjusted HR 0.80, 95\% CI 0.57-1.12, $P=.184$ ). Patients who received 1,2 to 3 , or $>3$ ICD discharges amounted to $8.9 \%, 7.1 \%$, and $11.1 \%$, respectively, in n-3PUFA, as compared with $11.1 \%, 10.7 \%$, and $12.1 \%$ in the placebo group (overall $P=.30$ ). ICD-driven therapy for VF was recorded in 71 patients (12.5\%), 34 $(12.2 \%)$ in the treatment group and $37(12.9 \%)$ in the placebo group $(P=.825)$.

When a post hoc analysis was done on the effects of n-3PUFA by type of device implanted, treatment significantly reduced VT/VF only in patients without CRT (unadjusted HR 0.68, 95\% CI 0.48-0.98, $P=.0372$ ), although the interaction between treatment and type of device was not significant $(P=.32)$.

\section{Secondary clinical end points}

In this relatively small subgroup of patients, total mortality was $26.6 \%$ in the n-3PUFA group and $24.3 \%$ in the placebo group (adjusted HR 1.25, 95\% CI 0.89-1.75, $P=$ .19). Among the other end points, the rate of $\mathrm{CV}$ hospitalization tended to be lower in the treatment group
(63.0\%) than the placebo group (71.5\%) (adjusted HR 0.87 , 95\% CI $0.71-1.07, P=.18$ ), in line with the results of the main study, although not statistically significant (Table III).

\section{n-3PUFA plasma concentrations}

Changes in n-3PUFA plasma levels from baseline to 3 months were obtained for 159 patients, 77 in the treatment group and 82 in the placebo group. Mean \pm SD n-3PUFA plasma levels expressed as the percentage of plasma phospholipids at baseline were $4.98 \pm 1.8$ in the $n$ 3PUFA group and $5.23 \pm 1.73$ in the placebo group. Mean changes expressed as least square means were 2.23 for the treatment group and -0.38 for the placebo group $(P<$ .0001). The rate of appropriate ICD interventions tended to be lower in patients with larger 3-month increases (ie, $>0.66$, median 3-month change) in plasma n-3PUFA ( $26 \%$ above the median change vs $32 \%$ below, $P=.405$ ).

\section{Discussion}

In this study, we observed a nonsignificant 20\% reduction in the number of patients with appropriate ICD interventions for VT/VF in the n-3PUFA compared with the placebo group. This was consistent with (a) the smaller number of patients with $>1$ ICD discharge, (b) the smaller number of ICD-treated episodes, and (c) the smaller number of arrhythmic events in subjects with the highest plasma levels of n-3PUFA. However, results indicate a minimal excess in total mortality in treated patients (26.6\% vs $24.3 \%$ ), opposite to the results of the main trial; on the other side, a $13 \%$ reduction in $\mathrm{CV}$ hospitalization was observed. These discrepancies may well be due to the small size of this higher-risk subpopulation of 566 patients as compared with the almost 7,000 patients in the main trial.

These findings are in line with experimental, ${ }^{14}$ epidemiological, and clinical studies showing a protective effect of n-3PUFA on arrhythmias and sudden cardiac death in the general population and in patients recovering from AMI. ${ }^{15-18}$ In GISSI-HF, survival curves for total mortality started to diverge after 2 years of treatment because of the lack of effect of n-3PUFA on most of the competing causes of death in HF patients, whereas the onset of benefit of n-3PUFA on fatal and nonfatal ventricular arrhythmias was early in post-AMI patients. ${ }^{4}$ Accordingly, the level of n-3PUFA in plasma and blood membranes rises steeply after the start of therapy ${ }^{13}$; and after 3 months, the plasma concentrations of n-3PUFA had risen $>45 \%$ in GISSI-HF.

To date, this is the largest study assessing the effects of $\mathrm{n}$-3PUFA in ICD patients, though with mixed indications that may have confounded the proper assessment of $n$ 3PUFA antiarrhythmic effect. Accordingly, even this relatively large study was underpowered to assess the potential benefit. A posteriori, the statistical power to detect a $20 \%$ reduction of appropriate ICD discharge was $40 \%$ in the present trial, whereas 2,000 patients are 


\section{Figure 1}

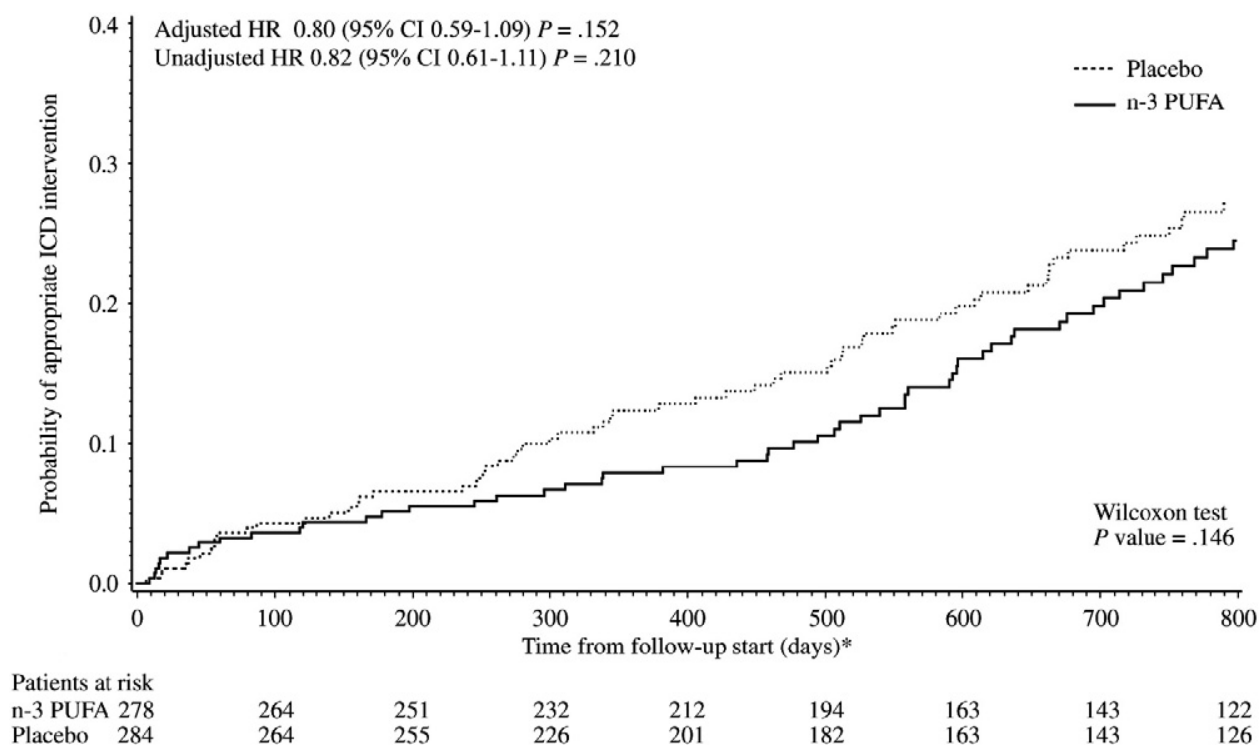

Kaplan-Meier curves for the time to first appropriate ICD intervention (VT or VF) by randomized treatment. *For ICD implanted during the study, the start of follow-up date is the date of ICD implant, whereas for ICD implanted before entering GISSI-HF, the starting time corresponds to randomization to the main trial.

Table III. Secondary end points and treatment

\begin{tabular}{|c|c|c|c|c|c|c|}
\hline Secondary endpoints & $\begin{array}{c}\text { n-3PUFA } \\
(278)\end{array}$ & $\begin{array}{l}\text { Placebo } \\
\text { (288) }\end{array}$ & Unadjusted HR (95\% Cl) & $P$ value & Adjusted HR (95\% CI) & $P$ value \\
\hline Mortality & $74(26.6 \%)$ & $70(24.3 \%)$ & $1.18(0.85-1.64)$ & .32 & $1.25(0.89-1.75)$ & .19 \\
\hline Mortality for worsening of HF & $42(15.1 \%)$ & $45(15.6 \%)$ & $1.04(0.68-1.59)$ & .85 & $1.15(0.75-1.78)$ & .51 \\
\hline Mortality for arrhythmias & $10(3.6 \%)$ & $6(2.1 \%)$ & $1.84(0.67-5.05)$ & .24 & $1.81(0.63-5.15)$ & .27 \\
\hline Hospitalization for any cause & $193(69.4 \%)$ & $218(75.7 \%)$ & $0.92(0.76-1.11)$ & .38 & $0.92(0.75-1.13)$ & .43 \\
\hline Hospitalization for CV causes & $175(63.0 \%)$ & $206(71.5 \%)$ & $0.88(0.72-1.08)$ & .21 & $0.87(0.71-1.07)$ & .18 \\
\hline Hospitalization for worsening of HF & $110(39.6 \%)$ & $127(44.1 \%)$ & $0.95(0.74-1.23)$ & .71 & $0.96(0.74-1.24)$ & .72 \\
\hline Hospitalization for arrhythmias & $48(17.3 \%)$ & $46(16.0 \%)$ & $1.12(0.75-1.68)$ & .58 & $0.98(0.65-1.48)$ & .92 \\
\hline Hospitalization for other CV causes & $107(38.5 \%)$ & $127(44.1 \%)$ & $0.88(0.68-1.14)$ & .32 & $0.87(0.67-.13)$ & .30 \\
\hline
\end{tabular}

Hazard ratios were calculated by using Cox univariate and multivariable models. Data are for patients who had at least one event. All analyses were based on the time to the first event. Hospitalizations for ICD implant/maintenance and those that occurred before the ICD implant are not included.

needed to reach at least a $75 \%$ power in case a prospective randomized trial were to be planned.

So far, 3 clinical trials have been conducted in different patient populations and using different dosages of $\mathrm{n}$ 3 PUFA, ${ }^{7-9}$ with contrasting results when compared. ${ }^{10,11}$ The clinical characteristics of GISSI-HF patients are different from those of these studies. First, patients were included on the basis of the diagnosis of HF with or without a history of malignant ventricular arrhythmias. Consequently, a substantial proportion of patients had an ICD implanted for primary prevention, as recommended by recent scientific statements and guidelines; and the proportion rose rapidly during the trial. In contrast, all patients in previous trials received an ICD as secondary prevention. ${ }^{7-9}$ Primary prevention has a lower risk profile than secondary prevention after a major ventricular arrhythmia and/or aborted sudden death. Patients with an indication for CRT, 39.5\% of all implants, have a higher arrhythmic risk profile than those in a better functional status who do not need this treatment and only receive a simple ICD device for primary prevention. In a post hoc analysis on our study, treatment with n-3PUFA significantly reduced time to first appropriate ICD discharge only in patients without CRT. Although the interaction is not statistically significant, the finding may suggest that the more advanced disease in patients with CRT and its proarrhythmic potential outweighed the possible protective effects of n-3PUFA.

Ischemic etiology of HF accounted only for $61.8 \%$ of the patients as compared with $76 \%$; mean LVEF was 
$28.4 \% \pm 6.7 \%$, whereas in the other 3 studies, ${ }^{7-9}$ it was around $35 \%$. This could indicate that, parallel to a more compromised functional status, our patient population had more severe ventricular arrhythmias. Overall, the severity of $\mathrm{HF}$, as expected, was higher in implanted patients than in the whole GISSI-HF population (total mortality of $24.3 \%$ in the placebo- and $26.6 \%$ in the $n$ 3PUFA-treated groups in 2 years compared with $6 \%$ to $9.4 \%$ in the other studies). ${ }^{7-9}$ The dose of $n-3$ PUFA in GISSI-HF was $850 \mathrm{mg} / \mathrm{d}$, as compared with 900 to 2600 $\mathrm{mg} / \mathrm{d}$ in the 3 previous studies. ${ }^{7-9}$ Although no clear dose-effect relationship has been demonstrated, it cannot be excluded that a higher n-3PUFA intake might be more beneficial.

This study has several limitations. It is a substudy of the large GISSI-HF trial with different primary end points, whose criteria for eligibility did not include reasons for ICD implant. However, ICD events were prospectively collected and adjudicated by an independent committee $^{12}$ of experts blind to study treatments. The trial was conducted in 89 hospitals in the Italian National Health system, ensuring the generalizability of its findings, although the insufficient power of the study does not allow definite conclusions. As during the comparatively long period of the study there were considerable shifts in cardiologists' attitudes in favor of the use of ICD for primary prevention, as supported by data in Table II, and a widespread indication for CRT with ICD back-up protection, enrollment in this study of a majority of patients at lower-than-expected risk profile was unavoidable. This could have negatively affected the possibility of demonstrating any significant effect of n-3PUFA. Unbalance between study groups in hypertension and antiplatelet use, though unrelated to study outcome, could have affected the results.

\section{Conclusions}

Encouraging data, in terms of reduction of sudden cardiac death, have been shown in post-AMI and HF patients treated with n-3PUFA. In GISSI-HF, n-3PUFA decreased nonsignificantly the number of ICD interventions for VT/VF as well as other arrhythmic events, in the absence of a reduction in "painful shocks" and mortality. The present study supports the trend (not statistically significant) toward prevention of life-threatening ventricular arrhythmias found in animal models and in epidemiological and comparative studies.

\section{Acknowledgements}

GISSI is endorsed by Associazione Nazionale Medici Cardiologi Ospedalieri (ANMCO), Firenze, Italy; by Istituto di Ricerche Farmacologiche Mario Negri, Milan, Italy; and by Consorzio Mario Negri Sud, Santa Maria Imbaro, Italy. We are grateful to Valter Torri for his statistical advice and to Francesca Perego for secretarial assistance.

\section{References}

1. European Society of Cardiology. ESC guidelines for the diagnosis and treatment of acute and chronic heart failure 2008: the Task Force for the Diagnosis and Treatment of Acute and Chronic Heart Failure 2008 of the European Society of Cardiology. Eur Heart J 2008;29:2388-442.

2. Cleland JG, Daubert JC, Erdmann E, et al. The effect of cardiac resynchronization on morbidity and mortality in heart failure. $N$ Engl J Med 2005;352:1539-49.

3. London B, AlbertC, Anderson ME, etal. Omega-3 fatty acids and cardiac arrhythmias: prior studies and recommendations for future research: a report from the National Heart, Lung, and Blood Institute and Office of Dietary Supplements Omega-3 Fatty Acids and Their Role in Cardiac Arrhythmogenesis Workshop. Circulation 2007;1 16:e320-35.

4. Gruppo Italiano per lo Studio della Sopravvivenza nell'Infarto miocardico. Dietary supplementation with n-3 polyunsaturated fatty acids and vitamin $\mathrm{E}$ affer myocardial infarction: results of the GISSI Prevenzione Trial. Lancet 1999;354:447-55.

5. Gruppo Italiano per lo Studio della Sopravvivenza nell'Insufficienza cardiaca. GISSI-HF. Effects of $n-3$ polyunsaturated fatty acids in patients with chronic heart failure (the GISSI-HF trial): a randomized double-blind, placebo-controlled trial. Lancet 2008;372:1223-30.

6. Marchioli R, Aldegheri MP, Borghese L, et al. Time course analysis of the effect of n-3PUFA on fatal and non fatal arrhythmias in heart failure: secondary results of the GISSI-HF trial. Eur Heart J 2009;30 (Abstract Supplement): 165.

7. Leaf A, Albert CM, Josephson $M$, et al. Prevention of fatal arrhythmias in high-risk subjects by fish oil n-3 fatty acid intake. Circulation 2005; 112:2762-8.

8. Raitt $M H$, Connor WE, Morris $C$, et al. Fish oil supplementation and risk of ventricular fibrillation in patients with implantable defibrillators: a randomized controlled trial. JAMA 2005;293:2884-91.

9. Brouwer IA, Zock PL, Camm J, et al. Effect of fish oil on ventricular tachyarrhythmia and death in patients with implantable cardioverter defibrillators: the Study on Omega-3 Fatty Acids and Ventricular Arrhythmia (SOFA) randomized trial. JAMA 2006;295:2613-9.

10. Brouwer IA, Raitt MH, Dullemeijer C, et al. Effect of fish oil on ventricular tachyarrhythmia in three studies in patients with implantable cardioverter defibrillators. Eur Heart J 2009;30:820-6.

11. Leon $H$, Shibata MC, Sivakumaran S, et al. Effect of fish oil on arrhythmias and mortality: systematic review. BMJ 2008;a2931:337.

12. Tavazzi L, Tognoni G, Franzosi MG, et al. Rationale and design of the GISSI heart failure trial: a large trial to assess the effects of $n-3$ polyunsaturated fatty acids and rosuvastatin in symptomatic congestive heart failure. Eur J Heart Fail 2004;6:635-41.

13. Di Stasi $D$, Bernasconi R, Marchioli R, et al. Early modifications of fatty acid composition in plasma phospholipids, platelets and mononucleates of healthy volunteers after low doses of $n-3$ polyunsaturated fatty acids. Eur J Clin Pharmacol 2004;60:183-90.

14. Leaf $A$, Kang JX, Xiao YF, et al. Clinical prevention of sudden cardiac death by $n-3$ polyunsaturated fatty acids and mechanism of prevention of arrhythmias by n-3 fish oils. Circulation 2003;107:2646-52.

15. Siscovick DS, Raghunathan TE, King I, et al. Dietary intake and cell membrane levels of long-chain n-3 polyunsaturated fatty acids and the risk of primary cardiac arrest. JAMA 1995;274:1363-7.

16. Kromhout $D$, Bosschieter EB, de-Lezenne-Coulander $C$. The inverse relation between fish consumption and 20-year mortality from coronary heart disease. N Engl J Med 1985;312:1205-9.

17. Albert CM, Campos H, Stampfer M, et al. Blood levels of long-chain n-3 fatty acids and the risk of sudden death. NEnglJMed 2002;346:1 11 3-8.

18. Burr ML, Fehily AM, Gilbert JF, et al. Effects of changes in fat, fish, and fibre intakes on death and myocardial reinfarction: Diet and Reinfarction Trial (DART). Lancet 1989;2:757-61. 


\section{Appendix. Investigators and centers participating to the ICD substudy of GISSI-HF}

Switzerland Lugano (T. Moccetti, E. Pasotti, M. G. Rossi). Italy Borgomanero (A. M. Paino, U. Parravicini), Orbassano (L. Montagna, A. Previti, G. P. Varalda), Torino, Evangelico Valdese (L. Bo, N. Massobrio), Torino, Maria Vittoria (M. Imazio, R. Trinchero), Veruno (U. Corrà, A. Mezzani, P. Giannuzzi). Aosta (G. Begliuomini). Bergamo (A. Gavazzi, M. Gori), Brescia, Spedali Civili Cardiologia (L. Dei Cas, S. Nodari), Cernusco sul Naviglio (S. Dell'Orto, M. Sfolcini), Como, Valduce (E. Miglierina, M. Santarone, L. Sormani), Como, S. Anna (R. Jemoli, F. Tettamanti), Giussano (K. N. Jones, A. Volpi), Milano, Monzino (P. Agostoni, P. Palermo), Milano, San Carlo Borromeo (L. Squadroni), Montescano (J. Baccheschi, O. C. Febo, F. Olmetti), Monza, San Gerardo (V. Antonazzo, E. Piazzi, A. Vincenzi), Passirana-Rho (A. Frisinghelli, M. Palvarini, M. D. Veniani), Pavia, San Matteo (N. Ajmone Marsan, G. Piccoli, L. Scelsi), Pavia, Salvatore Maugeri (A. Gualco, C. Opasich), Pieve di Coriano (M. A. Iannone), Sondalo, E. Morelli, Cardiologia Riabilitativa (N. Partesana), Tradate (R. Raimondo), Varese, Del Ponte (I. Ghezzi), Bovolone (S. Boni, A. Pasini), Camposampiero (A. A. Zampiero), Este (F. Caneve), Mirano (S. Milan, P. Sarto), Negrar (E. Barbieri, P. Girardi), Portogruaro (D. Milan), Verona (M. Cicoira, L. Zanolla), Gorizia (R. Chiozza, G. Giuliano), San Daniele del Friuli (L. Mos, O. Vriz), Tolmezzo (E. Alberti, M. Werren), Trieste (F. Longaro, G. Sinagra), Udine (M. C. Albanese, P. De Biaggio, D. Miani), GenovaSestri Ponente (D. Caruso), Sarzana-Loc. S. Caterina
(A. Cantarelli), Bentivoglio (R. Vandelli), Cotignola (A. Barbieri), Rimini (F. Bologna, G. Piovaccari), Bagno a Ripoli (M. Nannini), Cecina (F. Mazzinghi), Cortona (D. Cosmi), Empoli (A. Cecchi, A. Zipoli), Firenze, Nuovo S Giovanni di Dio (C. Minneci, G. M. Santoro), Firenze, S. M. Nuova (M. Milli), Fucecchio (A. A. Brandinelli Geri), Livorno (M. Carluccio, E. Magagnini), Massa, S. S. Giacomo e Cristoforo (V. Molendi), Poggibonsi (G. Scopelliti), Città di Castello (G. M. Arcuri, D Severini), Todi (R. Panciarola), Ascoli Piceno (G. Gregori, L. Moretti, L. Partemi),

Macerata (G. L. Morgagni), Albano Laziale (P. Midi, G. Pajes), Cassino (V. Di Spirito), Civitavecchia (S. Calcagno), Roma, Santo Spirito (N. Aspromonte, R. Ricci), Roma, Gemelli (C. Ierardi), Velletri (D. Banda, F. Frasca), Teramo (L. L. Piccioni), Castellammare di Stabia (G. De Caro), Napoli, Monaldi, I Div Medica (O. Maiolica, R. Santoro), Napoli, Federico II (M. Chiariello, P. Perrone Filardi), Oliveto Citra (P. Bottiglieri), Piedimonte Matese, Ave Gratia Plena (L. De Risi, A. Vetere), Salerno (P. Predotti, F. Silvestri), Bari, Policlinico (D. Traversa), Bari-Carbonara (C. M. Altamura, G. Scalera), Casarano (S. A. Ciricugno, M. Gualtieri, L. Manca), Fasano (F. Loliva), Putignano (G. Cellamare, D. De Laura), Taranto, Moscati (P. Palmisano, A. Peluso), Tricase (P. Palma), Potenza, A. O. San Carlo (M. Chiaffitelli, A. Lopizzo), Cosenza, S. S. Annunziata (G. Misuraca), Reggio Calabria (G. Cutrupi, G. Pulitanò, A. Ruggeri), Vibo Valentia (G. Maglia), Agrigento (R. Rametta), Caltagirone (A. Ali), Palermo, Civico e Benfratelli (L. Lo Presti, G. Stassi), Palermo, Villa Sofia (M. T. Cinà, V. Cirrincione, F. Ingrilli), Palermo, Cervello, Cardiologia I (R. V. Cappello, G. Geraci, F. Romano), Palermo, Cervello, Cardiologia II (F. Enia, A. M. Floresta), Cagliari, Marino (P. Siddi). 